\title{
Article
}

\section{Surf and Swash Dynamics on Low Tide Terrace Beaches}

\author{
Ivana M. Mingo ${ }^{1, *,+}$, Rafael Almar $^{2,+}+(\mathbb{C})$ and Laurent Lacaze ${ }^{1,+}+(\mathbb{C})$ \\ 1 Institut de Mécanique des Fluides (IMFT), 31400 Toulouse, France; laurent.lacaze@imft.fr \\ 2 Institut de Recherche pour le Développement, LEGOS (IRD, CNRS, CNES, Université de Toulouse), \\ 31400 Toulouse, France; rafael.almar@ird.fr \\ * Correspondence: ivana.mingo@toulouse-inp.fr \\ + These authors contributed equally to this work.
}

Citation: Mingo, I.M.; Almar, R.;

Lacaze, L. Surf and Swash Dynamics on Low Tide Terrace Beaches. Coasts 2021, 1, 73-89. https://doi.org/ $10.3390 /$ coasts 1010005

Academic Editor: Javier

Benavente González

Received: 30 September 2021

Accepted: 14 December 2021

Published: 19 December 2021

Publisher's Note: MDPI stays neutral with regard to jurisdictional claims in published maps and institutional affiliations.

Copyright: (C) 2021 by the authors. Licensee MDPI, Basel, Switzerland. This article is an open access article distributed under the terms and conditions of the Creative Commons Attribution (CC BY) license (https:// creativecommons.org/licenses/by/ $4.0 /)$.

\begin{abstract}
Low tide terrace (LLT) beaches are characterised by a moderately steep beach face and a flat shallow terrace influencing the local hydro-morphodynamics during low tide. The upper beachface slope $(\beta)$ and the terrace width $\left(L_{t}\right)$ are the main morphological parameters that define the shape of LTT cross-shore beach profiles. This work aims at better understanding the behaviour of $\beta$ and $L_{t}$ and their link with the incoming wave forcing. For this purpose, our results are based on 3.5 years times series of daily beach profiles and wave conditions surveys at two different microtidal LTT beaches with similar sediments size but different wave climate, one at Nha Trang (Vietnam) and the other one at Grand Popo (Benin). While they look similar, two contrasting behaviour were linked to two sub-types of LTT regimes: the first one is surf regulated beaches (SRB) where the swash zone is highly regulated by the surf zone wave energy dissipation on the terrace, and the second is swash regulated beaches (SwRB) acting in more reflective regime where the terrace is not active and the energy dissipation is mainly produced in the swash zone, the terrace becomes a consequences of the high dynamics in the swash zone. Finally, extending the common view of an equilibrium beach profile as a power law of the cross-shore distance, the ability of a simple parametrized cubic function model with the Dean number as unique control parameters is proposed and discussed. This simple model can be used for the understanding of LLT environments but it can not be extended to the whole beach spectrum.
\end{abstract}

Keywords: low tide terrace (LTT); surf zone; swash zone; hydro-mophodynamics systems; cross-shore beach profiles; Dean number; terrace width; upper swash slope

\section{Introduction}

Sandy beaches are loose deposits of sand accumulated at the shoreline that have been carried alongshore and cross-shore by currents and waves. The location of theses beaches is a function of sand sources, coastal processes and geology [1]. The modal beach morphology of sandy beaches changes in response to environmental conditions (waves and tide forcing, sediments, geology, etc.). This has been studied for a long time and has led to the development of several beach classification models. All of them include the occurrence of distinct beach morphologies linked to the key environmental conditions like wave climate, tidal regime and beach sediment characteristic [2-4]. Wright and Short (1984) [2] formulated one of the first of such beach classification model based on the dimensionless fall velocity also know by the Dean number $(\Omega)$. The dimensionless fall velocity is an important parameter influencing both surf zone hydraulics and the form of the resulting equilibrium profile, this was first proven by Gourlay (1981) [5].

The Dean number $\left(\Omega=H_{s} / W_{s} T_{p}\right)$ is a dimensionless parameter that relates breaker wave height $\left(H_{s}\right)$, wave period $\left(T_{p}\right)$ and sediment fall velocity $\left(W_{s}\right)$, in other terms it refers to the ratio of a particle settling time $\left(H_{s} / W_{s}\right)$ to the wave period. On microtidal beaches, where the environment is wave-dominated, beach systems can be classified in three distinctive beach types: dissipative $(\Omega>5)$ and reflective $(\Omega<1)$ states linked by 
an intermediate state $(1<\Omega<5)$. Dissipative beaches are normally characterized by a smooth slope and spilling breakers while reflective beaches are the opposite having a steep slope and surging breakers $[2,6]$.

This research work is focused on Low tide terrace (LTT) environments. LTT beaches are a specific but common type of sandy beaches widely studied in the coastal community $[2,3,6-10]$. Nevertheless our understanding on LTT beach dynamics is still not sufficient and needs to be improved.

Following Wright and Short classification model at microtidal beaches, the LTT state is a particular case inside the intermediate state. Theoretically, as the rip channels of transverse bar and rip state (TBR) are infilled the LTT state is reached. The terrace formation is due to a coupling between the effects of tides and waves and are commonly formed out of coarse sand. A terrace beach can be seen also at macro- and meso tidal regimes [6,11].

LTT beaches have been observed to exhibits characteristics of both dissipative and reflective sites [7]. During low tide, lower levels favour wave breaking on the gently sloping LTT, creating a very dissipative conditions of the surf zone but at high tide, they may pass across the terrace unbroken to surge up the steep beach face producing reflection. Recent work suggests that the terrace acts as a low-pass filter to the swash-zone dissipating a large part of the wave energy in the short wave band (frequency between 0.05 and $0.3 \mathrm{~Hz}$ ) resulting in a dominance of infra-gravity waves $(\mathrm{f}<0.05 \mathrm{~Hz})$ that do not fully dissipate in the surf-zone [12]. The morphological response of the swash zone to varying offshore waves is highly modulated by the surf zone conditions, being the terrace width a key parameter of the wave energy dissipation rate. Continuing these resents results [7,12-15], the present work intends to describe the swash and surf dynamics of LTT beaches by doing a simple characterisation of these zones using two main morphological parameters of LTT cross-shore beach profiles: the upper swash slope $(\beta)$ and the terrace width $\left(L_{t}\right)$ of the surf zone. These are key parameters that defines the shape of cross-shore LTT profiles and their relationship with the hydrodynamics wave forcing will provide information of their behaviour. In the following sections we aim to explain how these parameters work, search their relationship between them and their interactions with the offshore wave forcing. This paper aims at improving our knowledge on LTT beach morphodynamics by analysing two field data set at LTT environments with two different wave climate. Understating the morphodynamic response of LTT beaches to different wave climates is an important issue for coastal erosion, especially as rising sea levels can invade upon coastal infrastructure and climate change may modify the variation of extreme events frequency and intensity [16].

\section{Methodology}

\subsection{Field Data}

Several field experiments were conducted at two sandy beaches between 2013 and 2016, one at Nha Trang, Vietnam and the other at Grand Popo, Benin. The objective of these field campaigns were to investigate short-term swash-zone hydrodynamics, and morphodynamics under variable wave conditions based on bathymetry inversion methods. These datasets revealed the characteristics of Nha Trang and Grand Popo beaches as low tide terrace beaches $[12,14,17]$. A secondary objective of these experiments was to validate video camera estimates, and in particular asses error on beach profiles $[17,18]$ obtained from a combination of depth inversion from wave kinematics $[14,19]$ and intertidal beach mapping using the shoreline [20].

Figure 1 presents the beach profiling location (cross-shore transect) of Nha Trang and Grand Popo where cross-shore time-stack images are created for depth inversion. Inversion method relies on the linear wave theory that provides a dispersion relation between wave propagation and bathymetry for shallow and intermediate depths. 

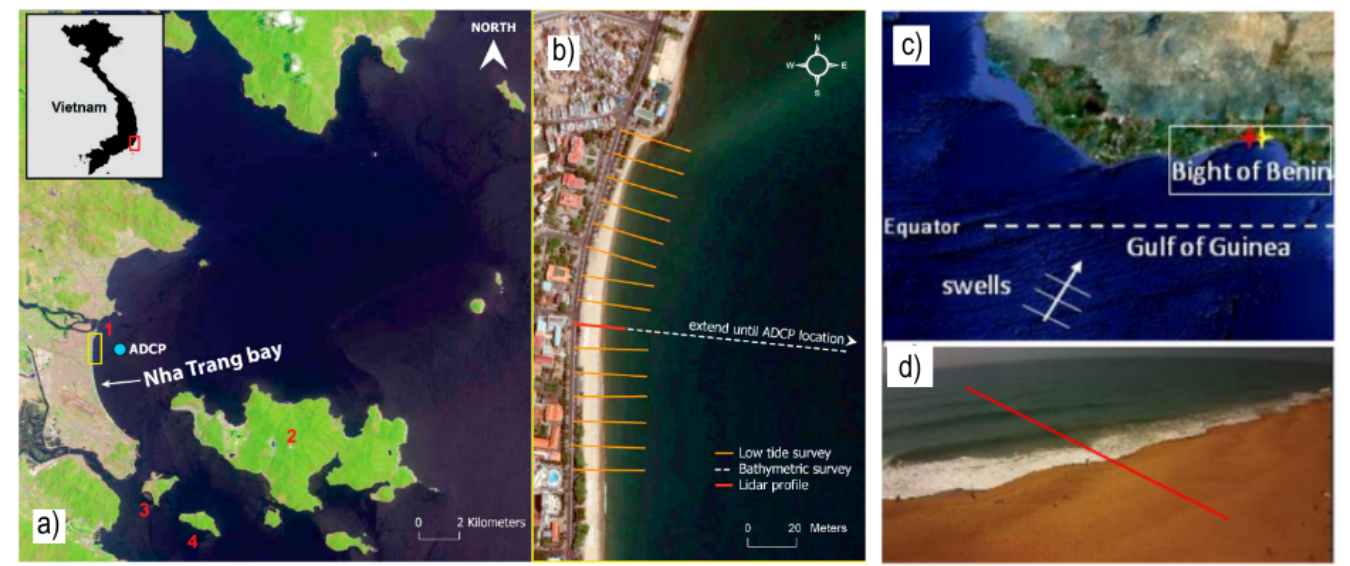

Figure 1. (a) Location of Nha Trang bay and some important local features including: 1-Cai estuary; 2-Hon Tre island; 3-Hon Mieu island; 4-Hon Tam island. The yellow box indicates the section of the beach studied (zoomed in figure (b)). (b) Aerial photograph of the study site where the red solid line presents the profiling location where cross-shore time stack images are created for depth inversion. (c) Focus in the Bight of Benin where Grand Popo beach is located. (d) Grand Popo beach. The red solid line presents the profiling location where the cross-shore time stack images are created for depth inversion.

For Nha Trang a shore-based video system [21,22] was installed in May 2013 in the central part of Nha Trang bay by researchers of Thuy Loi University in collaboration with LEGOS/IRD-France. The video station contains two color cameras (VIVOTEK IP7361, max-resolution $1600 \times 1200$ pixels) fixed on an existing light pole nearby, located $70 \mathrm{~m}$ from shore and at $14.3 \mathrm{~m}$ above mean sea level (MSL). Time-stack images are interpolated on a regular grid using MSL reference and parameters obtained in the rectification step, with the native time resolution $(2 \mathrm{~Hz})$ and a regular space resolution of $0.5 \mathrm{~m}$ [18].

For Grand Popo a low-cost video system was installed on the top of a tower of the Navy forces of Benin, about $70 \mathrm{~m}$ from the shoreline. As detailed in Ondoa et al. (2017) [23], the system was composed of a VIVOTEK IP 7361 camera $(1600 \times 728$ pixels), which collected data continuously at $2 \mathrm{~Hz}$.

Video-based bathymetry inversion has been developed for more than 20 years $[18,19]$ with a range of errors between 0.1-2.0 m (RMSE). At Nha Trang it was proved that the error obtained on the bathymetry data increased with the distance to shore but the main aspect of the beach profile, i.e., the terrace, was well captured by the inversion method $[17,18]$. The Root Mean Square Errors (RMSE) on the elevation for Nha Trang and Grand Popo is $0.26 \mathrm{~m}$ and $0.14 \mathrm{~m}$ respectively. these values were obtained from comparison between observed beach profiles during field surveys and those calculated with inversion methods [18,23]. Note that wind waves period less than 3-4 s cannot be used for depth inversion as it produces significant errors on the extraction of the bathymetry (shaded bands converging the summer season at Nha Trang, Figure 2 in Section 2.1).

Figure 2 illustrates the data sets from these fields experiments where it is possible to appreciate 3.5 years bathymetry evolution, offshore wave forcing parameters such as wave period $\left(T_{p}\right)$ and height $\left(H_{s}\right)$ and the Dean number evolution $(\Omega)$ defined in the previous section. For both cases (Nha Trang and Grand Popo), wave height and period (zero-crossing) are derived from the video images and thus better accounts for local waves than model hindcasts. These estimations were already calibrated/validated using insitu measurements during field experiments (see more details in $[17,18]$ ). 

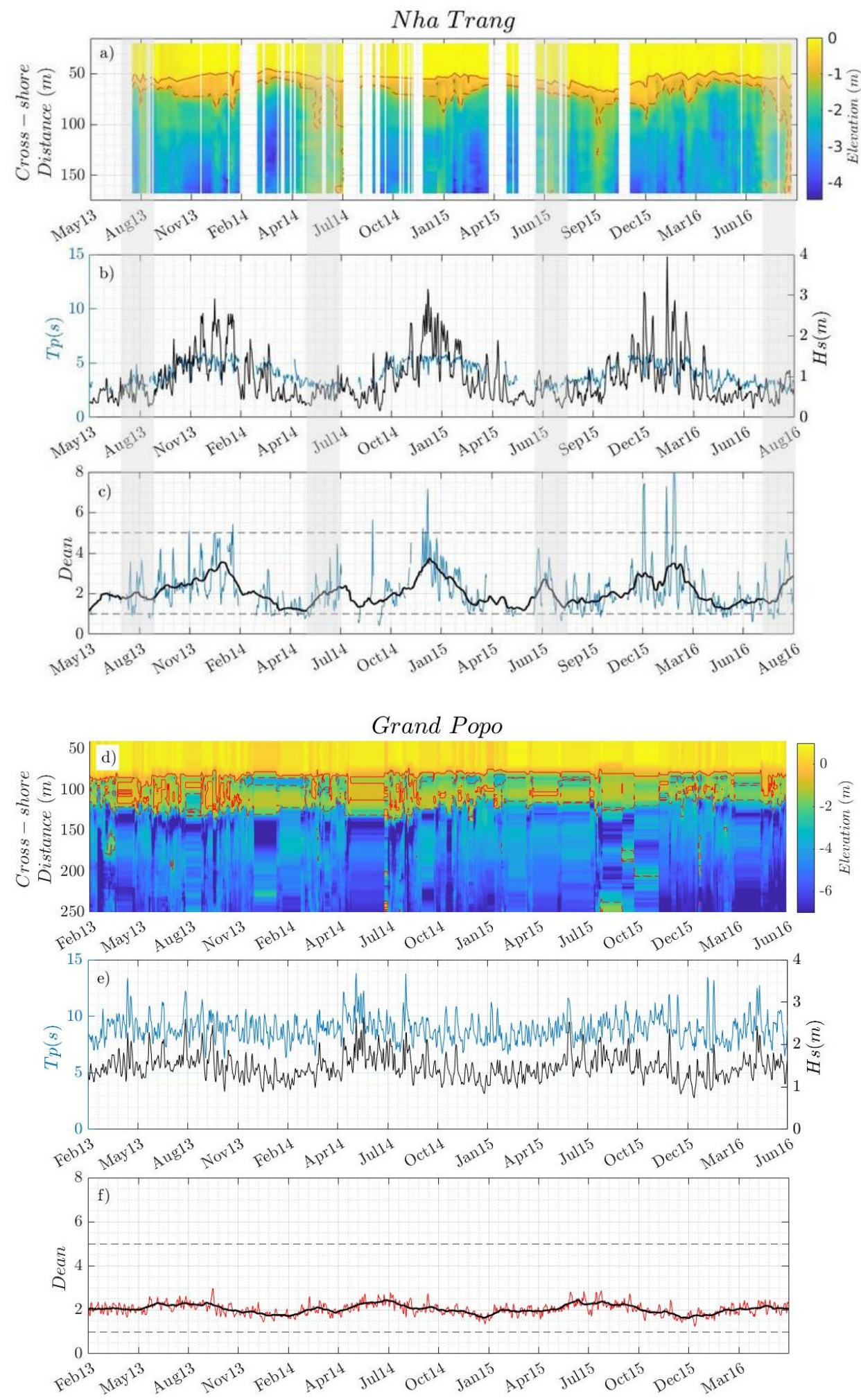

Figure 2. (a,d) show the long-term evolution of the daily bathymetry at Nha Trang and Grand Popo. The LTT is indicated between a red contour between $-0.4 \mathrm{~m}$ and $-1 \mathrm{~m}$ for Nha Trang and $-0.85 \mathrm{~m}$ and $-2.5 \mathrm{~m}$ for Grand Popo. Note the shaded bands covering the summer season. They roughly indicate that wind waves with period less than 3-4 s cannot be used for depth inversion (more on error estimation in [18]). (b,e) illustrates the offshore wave forcing evolution at Nha Trang and Grand Popo, wave period in cyan and wave height in black. Figure (c,f) show the Dean number evolution calculated for Nha Trang and Grand Popo, daily evolution in cyan and monthly moving average evolution in black. 
Figure 2a,d show the daily cross-shore video-derived beach profile, where the low tide terrace area is indicated. For the location of the terrace zone, the elevation values were fixed at $-0.4 \mathrm{~m}$ to $1 \mathrm{~m}$ for Nha Trang and $-0.85 \mathrm{~m}$ to $-2.5 \mathrm{~m}$ for Grand Popo as those values have proven to best capture the terrace evolution on the daily bathymetry figure obtained from video inversion.

The tidal level at Nha Trang and Grand Popo were extracted from previous work $[13,18]$ for a first location of the swash zone. To define the upper swash slope $(\beta)$ the berm crest point and the upper limit of the terrace was used as reference for each beach profile, then $\beta$ is defined as the linear part of this zone representing the beachface slope (Figure 3). Thus to extract the upper swash slope $(\beta)$, the linear limits were not fixed and were calculated for each profile from its berm crest.

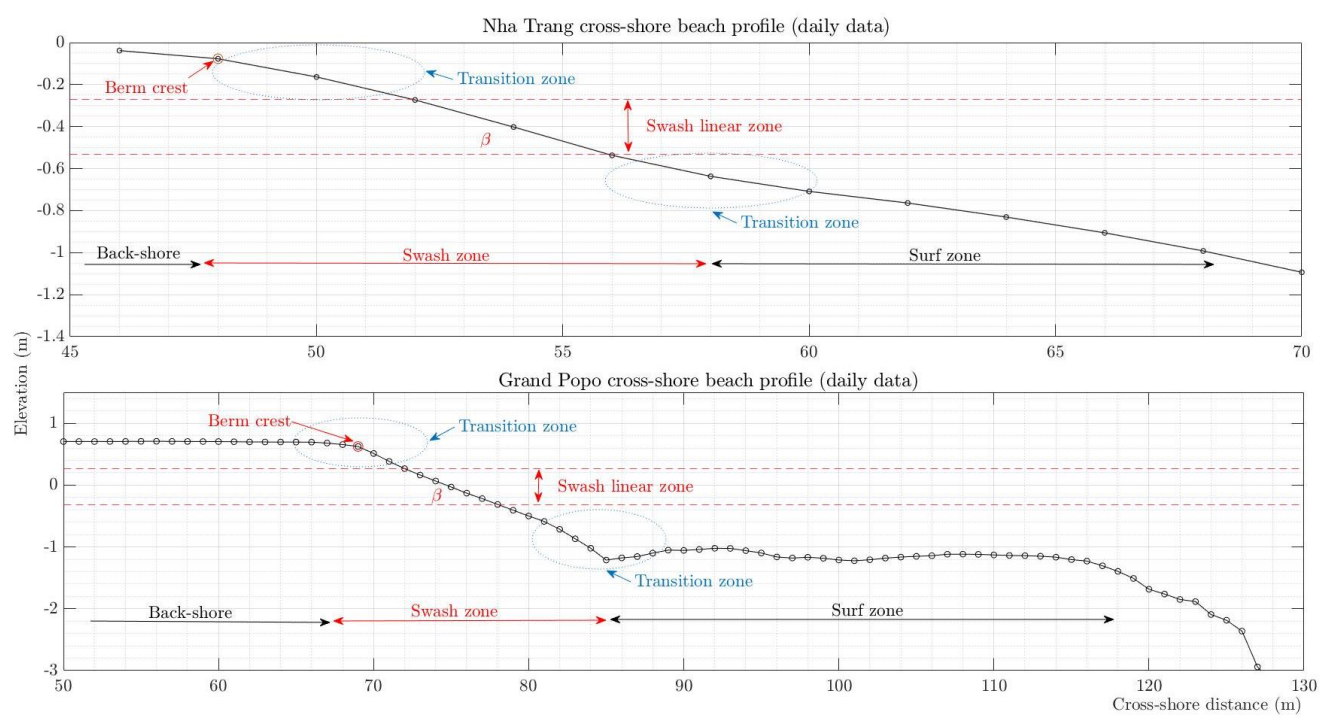

Figure 3. Typical WNT and GP cross-shore profiles. Definition of the swash zone and upper swash slope $(\beta)$ for Nha Trang (top figure) and Grand Popo (bottom figure).

To summarise, Nha Trang is a along-shore uniform LTT beach located on a semiclosed bay with a microtidal range from $0.4 \mathrm{~m}$ to a maximum of $1.7 \mathrm{~m}$ and a low to moderate energy wave climate where waves show seasonal variability. The annual mean significant wave height $\left(\widehat{H_{s}}\right)$ is $0.95 \mathrm{~m}$, with an associated averaged peak period $\left(\widehat{T_{p}}\right)$ of $6.2 \mathrm{~s}$. On the other hand Grand Popo is an open microtidal coast forming a $500 \mathrm{~km}$ long mild embayment in the Gulf of Guinea. This coast is exposed through the year to constants, moderate to high energy waves (mean significant wave height $\widehat{H_{s}}=1.36 \mathrm{~m}$; mean peak period $\widehat{T_{p}}=9.4 \mathrm{~s}$ ). Grand Popo coastal area is a swell-dominated environment where oblique waves (South/Southwest) and tides are the main drivers of nearshore dynamics. The sediment size is medium-to-coarse with a mean grain size of $D_{50}=0.6 \mathrm{~mm}$ for both, Nha Trang and Grand Popo. Therefore this are two LTT microtidal beaches with similar sediment size but different wave climate and coastal environments. The coastal characteristics of Nha Trang and Grand Popo are summarised in Table 1. 
Table 1. Nha Trang and Grand Popo coastal characteristics. $\widehat{H_{s}}, \widehat{T_{p}}, \widehat{\lambda}$ are the offshore seasonal mean wave height, period and wavelength and $\widehat{\Omega}$ the seasonal mean Dean number.

\begin{tabular}{|c|c|c|c|c|c|c|c|}
\hline & $\begin{array}{c}D_{50} \\
(\mathrm{~mm})\end{array}$ & $\begin{array}{l}\text { Micro-Tidal } \\
\text { Range (m) }\end{array}$ & $\widehat{H_{s}}(\mathrm{~m})$ & $\widehat{T_{p}}(\mathrm{~s})$ & $\widehat{\lambda}(\mathrm{m})$ & $\widehat{\Omega}$ & $\begin{array}{l}\text { Beach } \\
\text { State }\end{array}$ \\
\hline \multirow{3}{*}{ Nha Trang } & \multirow{3}{*}{0.60} & \multirow{3}{*}{0.4 to 1.7} & 0.92 (annual) & 4.09 & 27.76 & 2.85 & - \\
\hline & & & 0.63 (summer) & 3.14 & 15.77 & 2.50 & Intermediate to Reflective \\
\hline & & & 1.30 (winter) & 4.91 & 38.45 & 3.50 & LTT \\
\hline \multirow{3}{*}{ Grand Popo } & \multirow{3}{*}{0.60} & \multirow{3}{*}{0.8 to 1.8} & 1.47 (annual) & 8.89 & 125.51 & 2.05 & LTT \\
\hline & & & 1.64 (summer) & 9.04 & 129.00 & 2.27 & LTT \\
\hline & & & 1.25 (winter) & 8.07 & 112.23 & 1.85 & LTT \\
\hline
\end{tabular}

\subsection{Dimensional Analysis and LTT Classification}

The hydro-morphodynamic processes can differ dramatically as function of the beach states. To classify these states we used the Dean dimensionless number. The evolution of the dimensionless fall velocity, also known as the Dean number, shown in Figure 2 is analysed in order to understand the temporal variability of cross-shore beach profiles. As mentioned previously, this dimensionless parameter can be written as:

$$
\Omega=H_{s} /\left(T_{p} W_{s}\right),
$$

with $W_{s}$ the sediment settlement velocity, or equivalently

$$
\Omega=H_{s} / H_{g}
$$

with $H_{g}$ the typical height over which sediment settled during a wave period. Then, if $\Omega=H_{s} / H_{g}>>1$, sediments in suspension fall on a short height compared to the spatial dimension of the wave. This means that sediments might remain in suspension and therefore be more subjected to transport between the different zones of the inner-beach.

At Nha Trang the seasonal variability of the hydrodynamics offshore wave forcing is more pronounced than at Grand Popo, as shown in Figure 2. This implies a variation of the Dean number at Nha Trang which can go from 1 up to 5 approximately, while the Dean number remains almost constant at Grand Popo, around 2. This phenomenon reflects the beach states morphodynamics classified by the Dean number. In particular, two clear beach states are identified at Nha Trang, one during summer and the other during winter, while only one beach state is observed at Grand Popo with a roughly unchanged LTT shape. At Nha Trang an erosive phase is observed from September until the end of February due to winter monsoon conditions. This leads to a LTT beach state during winter $(\Omega$ increases). Then an accretion phase imposes the terrace to merge with the beachface resulting in a more reflecting state during summer ( $\Omega$ decreases). This seasonal variability of beach states show how beach morphology adapts to changing wave conditions, implying a fast exchange of sediment between the upper beach part and the terrace [18]. In contrast at Grand Popo a uniform shaped LTT is observed throughout the whole time series. Actually, Grand Popo is usually classified as a LTT beach state with a highly dynamic swash zone $[14,18,23]$.

Nha Trang and Grand Popo beach states are illustrated in Figure 4. There are clearly three different cross-shore mean profiles. In particular and as discussed previously, Nha Trang clearly highlights a difference between the summer and winter profile, referred for now to as SNT and WNT respectively, while a similar beach profile is observed at Grand Popo during the whole year, referred to as GP. The morpho-hydrodynamics annual mean parameters of both sites are summarised in Table 2 accordingly.

WNT is characterised by a fairly steep upper beachface slope $(\beta \sim 0.1)$ and a $14 \mathrm{~m}$ wide terrace and GP profile has a steeper beachface slope $(\beta \sim 0.19)$ and a $42 \mathrm{~m}$ wide terrace. The only geometric relationship that is maintained between these two LTT states (WNT and GP) is the ratio between the terrace width and the wavelength $\left(L_{t} / \lambda=0.3\right)$. 
The Dean number at Grand Popo is smaller than Nha Trang Dean numbers meaning that there is more sediment transport between the surf and swash zone at Nha Trang, this is also reflected on the dimensionless parameter $\widehat{H_{t}} / \widehat{H_{g}}$. Note that the Dean number of SNT is actually closer to the value of GP one, but no terrace is observed in this case, while the upper beachface slope remains relatively smaller for SNT than GP. These observations are therefore not fully captured by using only the Dean number. However, we propose to analyse LTT in term of the Dean number to highlight the influence of this parameter on the evolution of the profiles specifying its advantages and limitations.

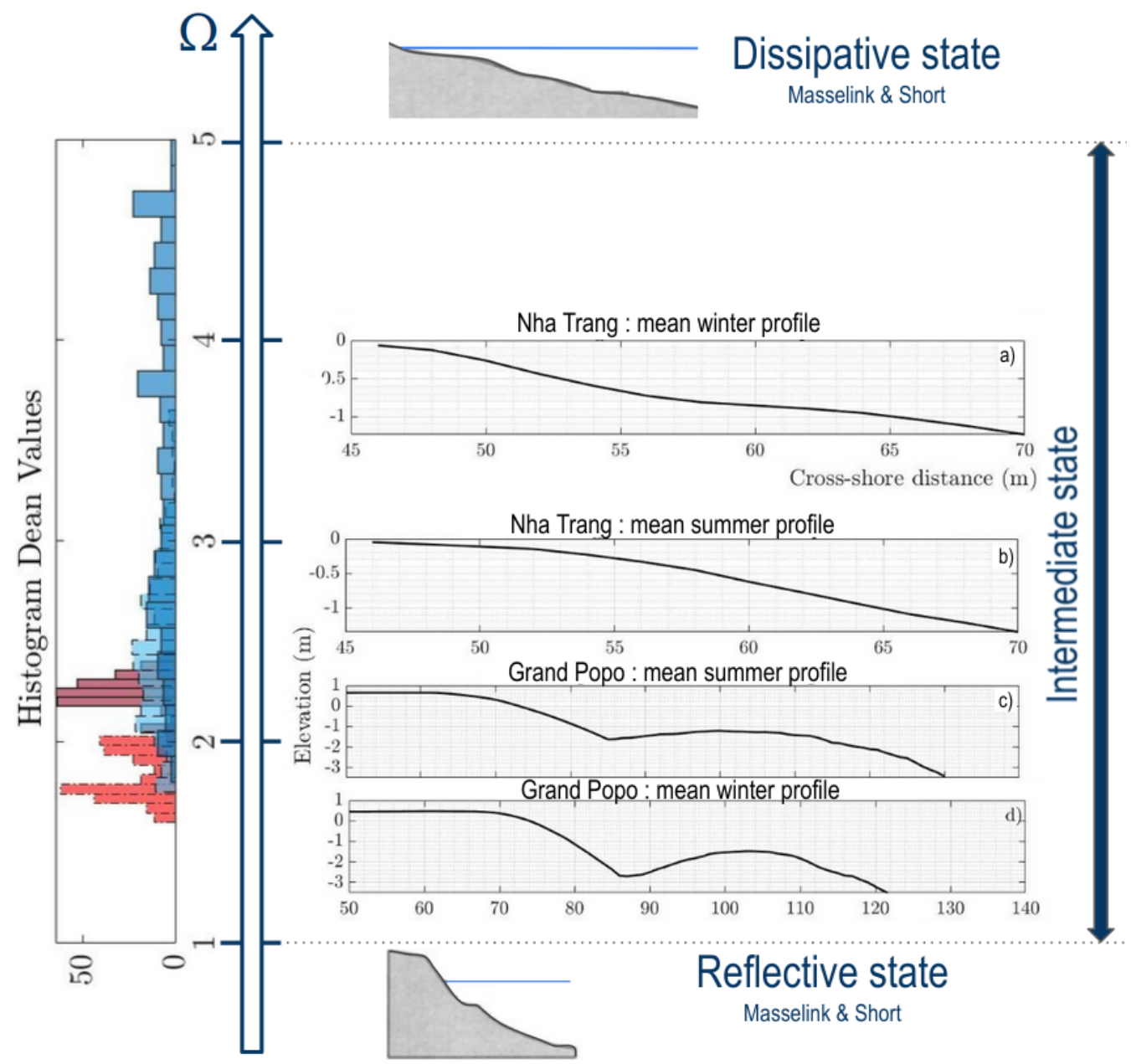

Figure 4. Nha Trang and Grand Popo Summer and winter mean cross-shore beach classified according to the Dean number $(\Omega)$. The figure on the left shows an histogram of the monthly Dean values of the Nha Trang (in blue) and Grand Popo (in red) cross-shore profiles.

Table 2. Nha Trang and Grand Popo moprho-hydrodynamics parameters. $\widehat{L_{t}}, \widehat{\beta}$ and $\widehat{H}_{t}$ are the annual mean terrace width, upper swash slope and water depth on the terrace.

\begin{tabular}{|c|c|c|c|c|c|c|c|c|c|c|c|}
\hline \multirow[b]{2}{*}{ Beach State } & \multicolumn{3}{|c|}{ Morpho Parameters } & \multicolumn{3}{|c|}{ Hydro Parameters } & \multicolumn{5}{|c|}{ Morho-Hydrodynamics Parameters } \\
\hline & $\widehat{L_{t}}$ & $\widehat{\beta}$ & $\widehat{H_{t}}(\mathrm{~m})$ & $\widehat{H_{S}}(\mathrm{~m})$ & $\widehat{T_{p}}(\mathrm{~s})$ & $\widehat{\lambda}(\mathrm{m})$ & $\widehat{H_{g}}$ & $\widehat{H_{t}} / \widehat{H_{g}}$ & $\widehat{h_{s}} / \widehat{\lambda}$ & $\widehat{L_{t}} / \widehat{\lambda}$ & $\widehat{\Omega}$ \\
\hline Reflective (SNT) & - & 0.10 & 0.6 & 0.63 & 3.1 & 15.77 & $0.25 \mathrm{~m}$ & 2.4 & 0.04 & - & 2.47 \\
\hline LTT (WNT) & $14 \mathrm{~m}$ & 0.10 & $0.9 \mathrm{r}$ & $1.30 \mathrm{~m}$ & $4.91 \mathrm{~s}$ & 38.4 & $0.40 \mathrm{~m}$ & 2.25 & 0.03 & 0.3 & 3.50 \\
\hline LTT (GP) & $42 \mathrm{~m}$ & 0.19 & $1.30 \mathrm{~m}$ & $1.47 \mathrm{~m}$ & $8.89 \mathrm{~s}$ & $125.51 \mathrm{~m}$ & $0.72 \mathrm{~m}$ & 1.80 & 0.01 & 0.3 & 2.05 \\
\hline
\end{tabular}




\subsection{Key Low-Tide Terrace Morphological Parameters Extraction}

The morphological key parameters of LTT beaches inner-zone are the upper beachface slope $(\beta)$ and the terrace width $\left(L_{t}\right)$. These parameters can define the shape of LTT crossshore beach profiles. To analyse the behaviour of these key parameters, the first step is to process the data sets by calculating correlations between the morpho parameters $\left(\beta, L_{t}\right)$ with the Dean number $(\Omega)$ for different times scales moving average to smooth out short terms fluctuations (out-of-equilibrium states). Interestingly for these correlations it was observed that for both cases, Nha Trang and Grand Popo, the correlations improved with the increase of the days mean moving average, converging around the monthly mean average, these correlations values are indicated in Figure 5.

The correlations between the terrace width $\left(L_{t}\right)$ and the Dean number $(\Omega)$ is considerably better for Nha Trang than for Grand Popo when analysing monthly data. This is a fact as theses values depend on the wave climate; the wave climate is monsoonal at Nha Trang, therefore the beach profile and the Dean number are more variable than at Grand Popo were the wave climate is more or less constant being the beach profile response also more or less constant. This fact highlights that there is a time delay between the wave action and the changes in the beach profile parameters. Note that the upper swash slope for Nha Trang cross-shore beach profile $(\beta)$ is never correlated with offshore parameters meaning that this parameter may be dominated by surf zone processes and not directly driven by incoming waves.
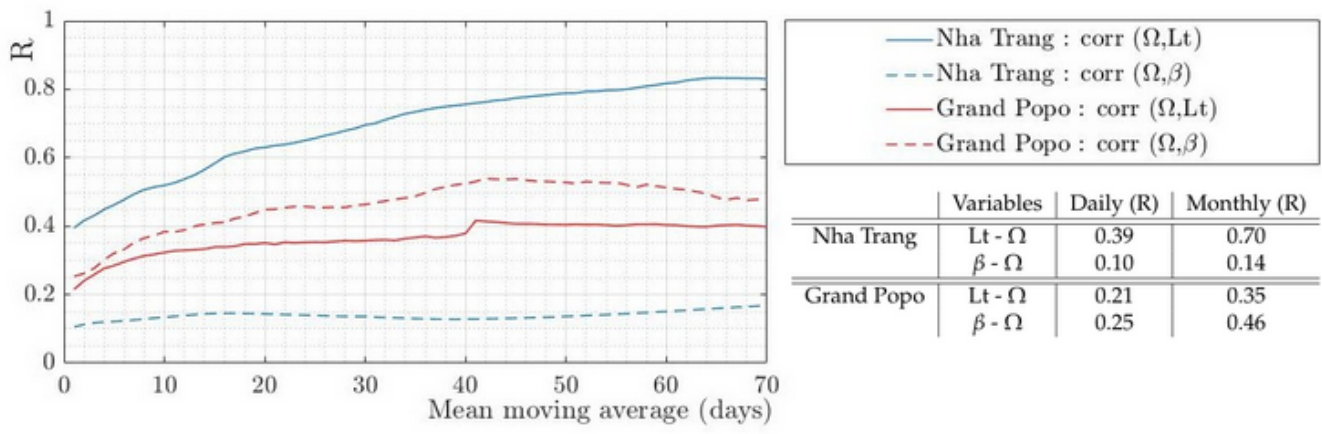

Figure 5. Left figure illustrate the correlation coefficient between the morpho parameters $\left(\beta, L_{t}\right)$ with the Dean number $(\Omega)$ for different times scales moving average

On the following sections all morpho and hydro parameters analysed are referred to the monthly mean moving average data $\left(\beta, L_{t}, \Omega\right)$.

\section{Morphology Scaling}

As it was seen from field data observations the morphodynamic behaviour of WNT and GP are very different. To characterise this two kinds of LTT beaches and understand the processes intervening we study the interactions of LTT morpho parameters $\left(L_{t}, \beta\right)$ with their corresponding Dean number $(\Omega)$.

\subsection{Scaling from Field Data}

Dimensionless parameters are calculated from the two morpho parameters in order to relate them with the Dean number and compare both LTT beaches. These morphological dimensionless parameters are: the ratio between terrace width and seasonal mean terrace depth $\left(L_{t} / \widehat{H_{t}}\right)$, the ratio between terrace width and offshore wavelength $\left(L_{t} / \lambda\right)$ and the upper swash slope $(\beta)$. The results between these dimensionless parameters with the the Dean number $(\Omega)$ are illustrate in Figure 6 highlighting the hydro-morphological relations at Nha Trang and Grand Popo.

On Figure 6, Nha Trang data is represented in blue and Grand Popo in red. Note that when $\Omega<2.5$, no terrace is observed for (SNT). These results allows us to identify 2 different behaviours of the dimensionless morphodynamics parameters $\left(L_{t} / \widehat{H}_{t}, L_{t} / \lambda\right.$ 
and $\beta$ ) in relation with their Dean number $(\Omega)$. The first case is for $\Omega>2.5$, for which the morpho parameters remain rather constant. In the other case, when $\Omega<2.5$, the upper swash slope $(\beta)$ and $L_{t} / \widehat{H_{t}}$ decrease with the Dean number $(\Omega)$. More surprisingly, the parameter $L_{t} / \lambda$ seems invariant with $\Omega$, suggesting geometric similarities for LTT beaches (WNT \& GP).

To finish, note that a dispersion of the data is observed in Figure 6, suggesting a strong variability of the LTT morphology on a short time scale, as highlighted in Figure 2.
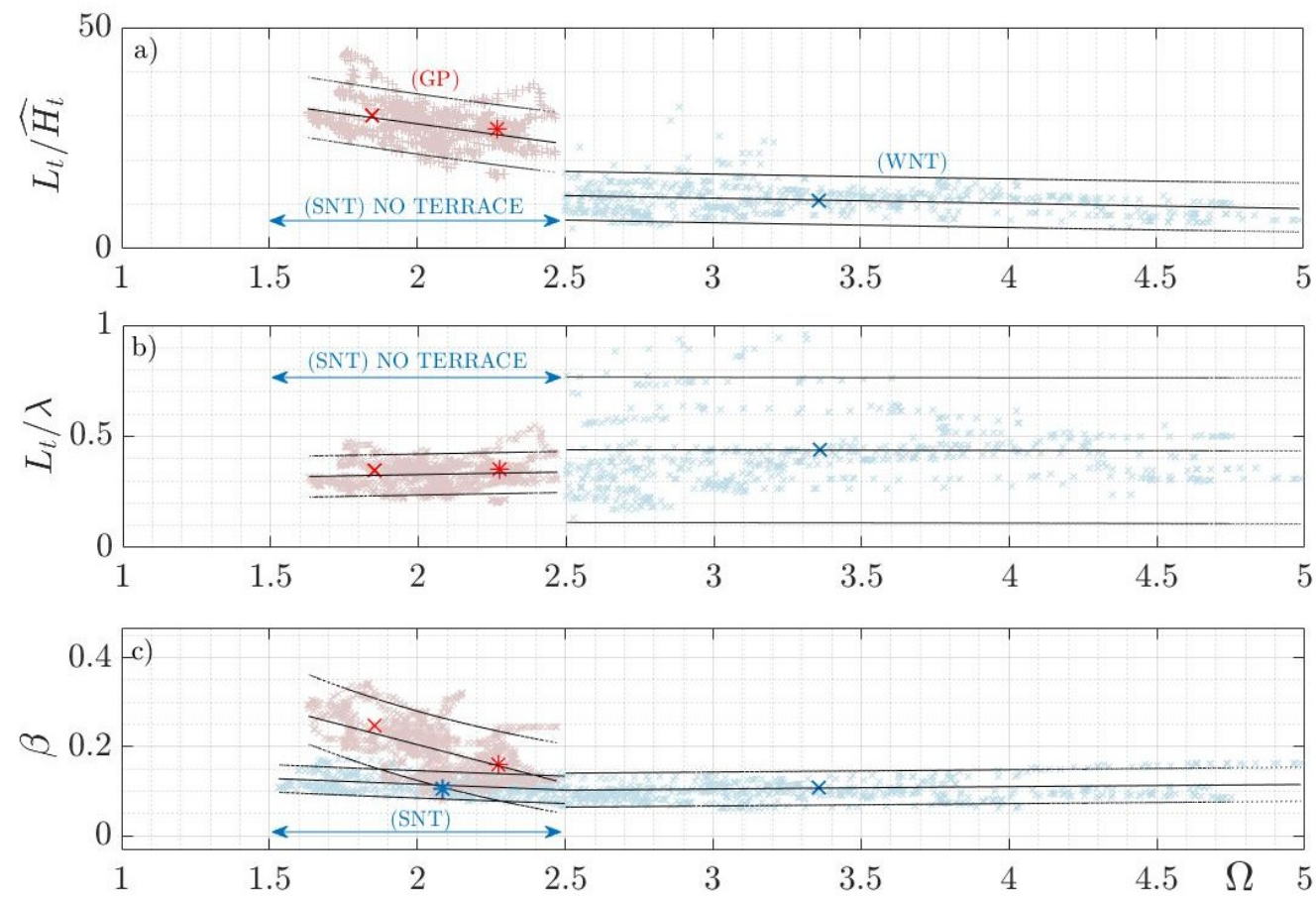

Figure 6. In these figures the blue and red color represents Nha Trang and Grans Popo dimensionless values. The little crosses $(x)$ represents the monthly average values, the big ones $(X)$ the summer average values and the big asterisks the winter average values. The two external black lines are the $90 \%$ confidence intervals (CI) and the middle one is the data regression. (a): Ratio between monthly moving average terrace width $\left(L_{t}\right)$ and annual mean terrace water depth $\left(\widehat{H_{t}}\right)$ vs. the Dean number $(\Omega)$. (b): Ratio between monthly moving average terrace width $\left(L_{t}\right)$ and annual mean terrace water depth $\left(\widehat{H_{t}}\right)$ vs. the Dean number $(\Omega)$. (c): upper beach face slope $(\beta)$ vs. Dean number $(\Omega)$.

\subsection{Discussion on the Swash versus Surf Morphodynamical Process}

We have therefore shown that even if Nha Trang and Grand Popo are classified as LTT microtidal environments, their nearshore behaviour is very different. A fundamental difference between them is their wave climate. However, a clear analogy in term of Dean classification can be done between Nha Trang during summer (SNT) and Grand Popo (GP). In contrast, Nha Trang during winter (WNT) has somehow a different evolution and structure with $\Omega$. The difference between these different observations is discussed in the following.

Field observations suggest that the dynamic of the nearshore zone exhibits characteristic of a dissipative and a reflective beach for WNT and SNT, respectively. According to such classification with $\Omega$ (a beach profile being more reflective for decreasing $\Omega$ ), this suggestion is here based on the profile structure shown in Figure 4. In particular, one observes that the terrace for WNT actually disappears for SNT, suggesting a lower dissipation on a shorter inner surf zone for the latter. Such observation would suggest a reflective beach for GP profiles, as $\Omega$ is closer to SNT than WNT. Yet, GP highlights a stable terrace profile. We suggest here that such terrace is therefore inactive, and probably to be attributed to a swash evolution, rather than a surf-dominated dynamics, as explained in the following. 
Based on Figure 6 and according to the previous discussion, two different behaviour are thus dissociated only depending whether the Dean number is actually lower or higher than 2.5 , independently of the considered site. Then, for $\Omega$ is $>2.5$, the three morphological dimensionless parameters $\left(L_{t} / \widehat{H_{t}}, L_{t} / \lambda\right.$ and $\left.\beta\right)$ remain roughly constant with $\Omega$. The terrace and swash shapes become independent of the Dean number $(\Omega)$. This behaviour suggests that the inner-surf dynamics is strongly affected by the terrace which dissipates wave energy, as mentioned previously. The swash zone is thus only regulated by the surf zone. On the other hand for $\Omega<2.5$ (SNT \& GP) we can see that the upper swash slope $(\beta)$ has a decreasing trend with $\Omega$ (Figure $6 \mathrm{c}$ ), suggesting a more intense action of the local slope in the swash zone on the inner surf dynamics (even if Nha Trang and Grand Popo highlight a slightly different evolution of $\beta(\Omega)$ in this regime as shown in Figure $6 c$ for $\Omega<2.5$ ). These two different morphodynamic behaviours, depending only on Dean number, allows us to classify LLT beaches in two different families. The first one is when the terrace becomes active at dissipating wave energy, hence the dynamics of the swash zone will be regulated by the surf zone $(\Omega>2.5)$. This case is referred to as Surf Regulated Beach (SRB). The second situation $(\Omega<2.5)$, referred to as Swash Regulated Beach (SwRB), is when the dissipation of the wave energy occurs mainly close to the beachface producing a highly dynamic swash zone. SNT and GP can be classified as SwRB.

To finish, The difference in $\beta(\Omega)$ observed between the two sites at $\Omega<2.5$, i.e., for SwRB state, could be attributed to different processes, which are not accounted in the present classification. The first one is that Grand Popo is probably close to equilibrium, while Nha Trang is clearly evolving between two states, i.e., is out-of-equilibrium. The second one is that the beach slope depends on other parameters, such as the longshore sediment transport for instance (probably more intense in Grand Popo due to oblique wave impact) or the beach profile history.

\section{Extending the Dean Profiles to 3rd Order Profiles}

\subsection{3rd Order Regression of the Bathymetry for the Study of a Parametric Model}

Having found interesting correlations between Lt and $\beta$ with the Dean number for LTT cross-shore profiles, the objective in this section is to build up a simple parametric model from this correlations and see if it is possible to recreate the beach profiles bathymetry evolution using as input the Dean number $(\Omega)$.

Cross-shore beach profiles can be approached using the theoretical equilibrium beach profiles proposed by Bruun (1967) [24] and Dean (1995) [25]. These equilibrium profiles derived from field observations have the following form:

$$
h=A y^{n}
$$

in which $A$, representing a sediment scale parameter, depends on the sediment size $\mathrm{D}$ and an exponent $n$ equal to $2 / 3$. This well known expression proposed by Dean it's normally used to generalise the entire beach profile, but as it has a simple form it's not adequate to capture local variation of the inner surf zone, which is the zone of interests in this research work. Therefore a 3rd order polynomial is chosen to model this specific zone. Even if no theoretical background supports such power law coefficient, the third order polynomial is the minimum order allowing to capture the shape profile including both swash and terrace as it includes the required curvatures of opposite sign. The model is not efficient to capture the beach profile shape in other locations (Figure 7). 


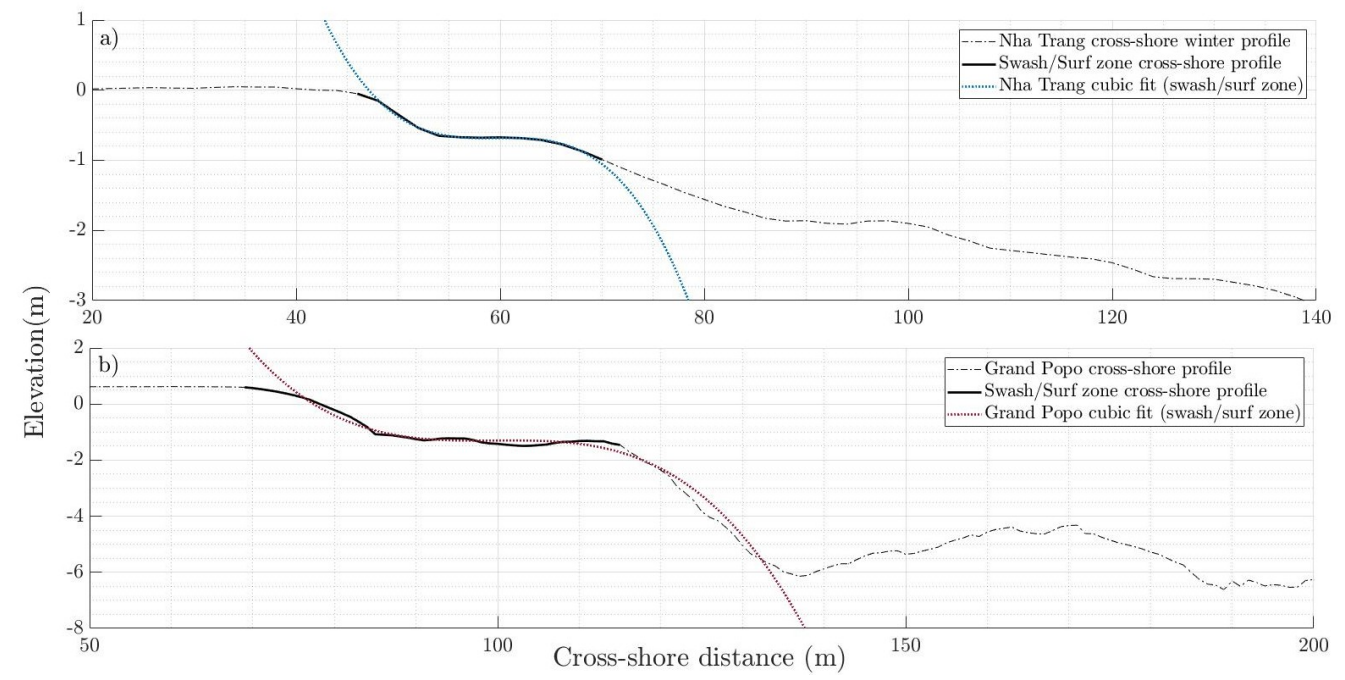

Figure 7. Typical WNT and GP cross-shore profiles. (a): The black dashed line represents Nha Trang mean winter cross-shore beach profile. The bold black line shows the zone of interest (surf and swash zone). The blue doted line is the cubic function that fits the zone of interest. (b): The black dashed line represents Grand Popo annual mean cross-shore beach profile. The bold black line shows the zone of interest (surf and swash zone). The red doted line is the cubic function that fits the zone of interest.

The parametric model consists of a two-parameter polynomial equation formed by only keeping the cubic and the linear terms, such as

$$
y(x)=A(x-\hat{x})^{3}+B(x-\hat{x})+\hat{y},
$$

where $x$ is the cross-shore distance and $y(x)$ the elevation of the beach profile. $\hat{x}$ and $\hat{y}$ refers to profiles offset allowing to center each profile around the zone of interest. The coefficients $A$ and $B$ define the shape of the beach profile. The variation of these coefficients can represent three key types of cross-shore profiles which are useful to represent the reflective profiles, LTT states and their transitions. In other words three profiles can be distinguished from the variation of the cubic and linear terms, as represented in Figure 8. In particular, Figure 8a shows an example of a LTT inner-shore environments observed for WNT profiles compared with a purely cubic profile, i.e., $B \rightarrow 0$. On the other hand, a SNT profile (reflective state) is well fitted by a linear shape, i.e., $A \rightarrow 0$ (see Figure 8c). Finally, ass shown in Figure $8 \boldsymbol{b}$, transient profile between these two cases can be captured by the full model (4) when both $A \neq 0$ and $B \neq 0$. The evolution of the beach states from a LTT to a reflective state can therefore be captured by model (4) with $A$ and $B$ to be determined.
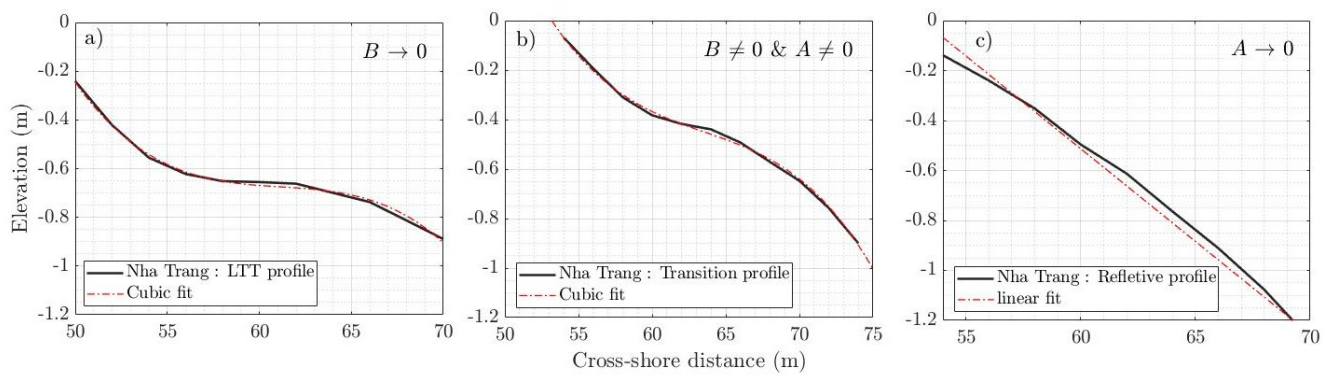

Figure 8. LLT cross-shore to reflective beach profiles obtained with the variation of the shape coefficients (see Equation (4)). (a): example of a LTT profile environment at WNT fitted with a purely cubic profile $(B \rightarrow 0)$. (b): example of a LTT profile environment at WNT fitted with a cubic profile $(A \neq 0$ and $B \neq 0)$. (c): example of a SNT profile (reflective state) fitted by a linear shape $(A \rightarrow 0)$. 
In order to show the relevance of model (4) over the entire set of measurements, the evolution of both $L_{t}$ and $\beta$ can be compared between measured profiles and fitted profiles. This is shown in Figure 9 for Nha Trang and Figure 10 for Grand Popo. Here, the 3rd degree regression model (4) was applied on the monthly moving average measurements data (as explained in Section 2.3).
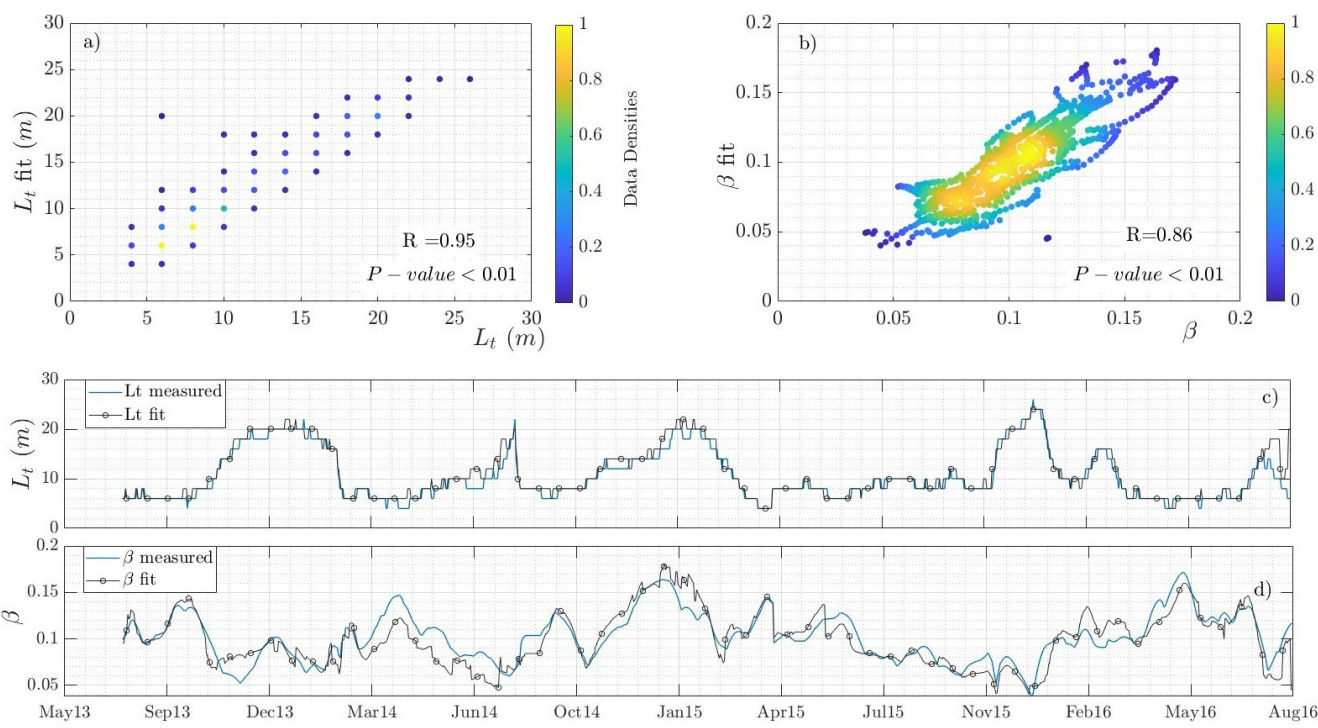

Figure 9. Nha Trang fit results. (a): Lt monthly average field data $\left(L_{t}\right)$ vs Lt fit. (b): betas monthly average field data $(\beta)$ vs betas fit. (c): terrace width $\left(L_{t}\right)$ evolution observed from field data and $L_{t}$ evolution calculated from fit profiles ( $L_{t}$ fit). (d): upper swash slope $(\beta)$ evolution observed from field data and $\beta$ evolution calculated from fit profiles ( $\beta$ fit).
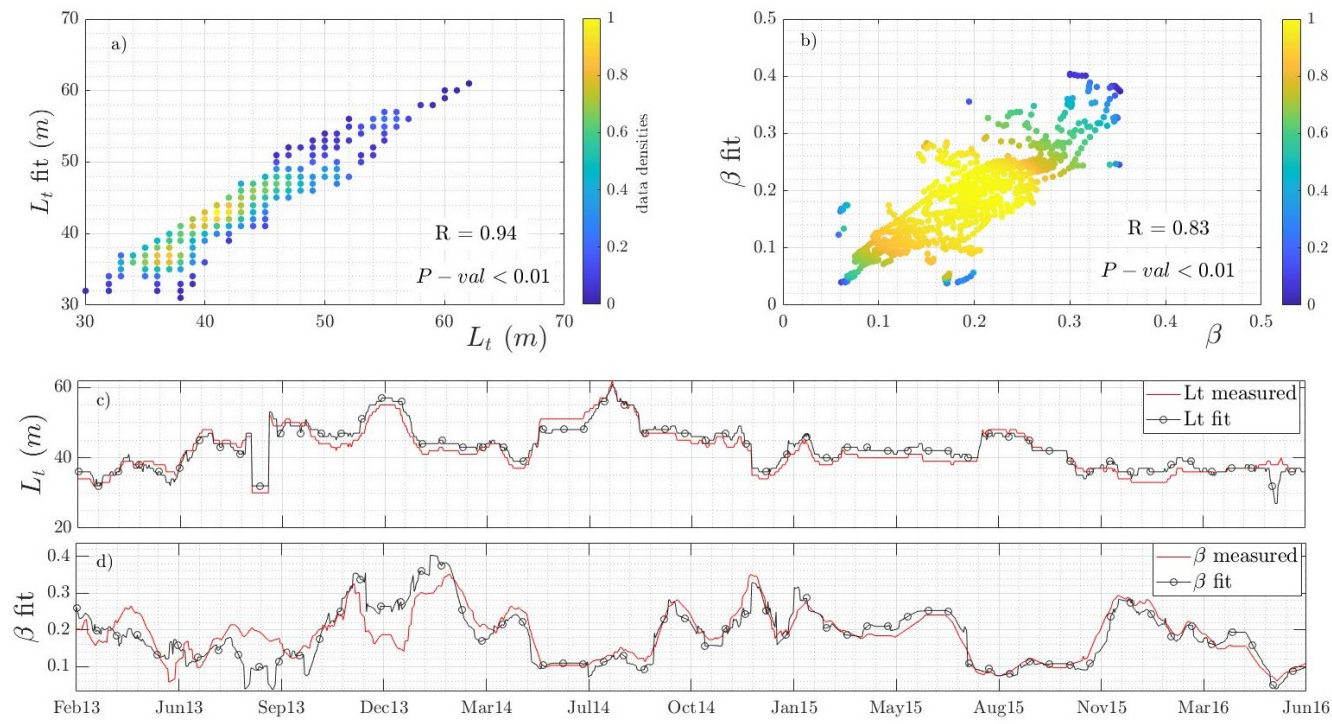

Figure 10. Grand Popo fit results. (a): Lt monthly average field data $\left(L_{t}\right)$ vs Lt fit. (b): betas monthly average field data $(\beta)$ vs betas fit. (c): terrace width $\left(L_{t}\right)$ evolution observed from field data and $L_{t}$ evolution calculated from fit profiles ( $L_{t}$ fit). (d): upper swash slope $(\beta)$ evolution observed from field data and $\beta$ evolution calculated from fit profiles ( $\beta$ fit).

The obtained terrace shape parameters, Lt fit and $\beta f$ it, are in good agreement with those obtained from field data measurements $(L t$ and $\beta$ ). Note that, even if the evolution of both parameters $L_{t}$ and $\beta$ is nicely captured by the cubic fit, $L_{t}$ highlights a slightly better accuracy that $\beta$ in both cases (Nha Trang and Grand Popo). Nevertheless, as already mentioned, Figure $9 \mathrm{c}$ clearly shows a seasonal fluctuation of the terrace shape which is 
actually captured by the proposed polynomial model. On the other hand, $\beta$ does not seem to follow a clear seasonal trend, and is more likely affected by short term fluctuations. On the contrary, Figure 10c shows that the terrace length $L_{t}$ at Grand Popo remains roughly invariant while the upper swash slope $\beta$ highlight a slight correlation with seasons, beyond a rapid short term fluctuations.

\subsection{A Simple Parametric Model to Understand the Behaviour of LTT Beach Profile}

In the previous section, we have shown the ability of a simple polynomial shape (4) to capture the basic trend of LTT beaches. Moreover, it was also shown in Section 3 how the Dean number $\Omega$ controls the main geometrical characteristics of the shape profiles $L_{t}$ and $\beta$. Now, in order to link these two results, a unique parametric equation that only depends on the dean number $(\Omega)$ is tested. For this purpose, the link between $A, B$ and $\Omega$ has to be evaluated.

Model (4) can therefore be simply written as:

$$
y(x)=F(\Omega)(x-\hat{x})^{3}+G(\Omega)(x-\hat{x})+\hat{y}
$$

The models were trained separately for Nha Trang and Grand Popo as we found that both beaches had very different responses of their inner-surf zone to offshore wave forcing. The training of the parametric model consists on obtaining the shape coefficients (A and B, Section 4.1) and relate them to the Dean number $(\Omega)$. Therefore the model coefficients $\mathrm{F}(\Omega)$ and $\mathrm{G}(\Omega)$ modelling $A$ and $B$, respectively, as a function of $\Omega$, are obtained from a linear regression between the shape coefficients $\mathrm{A}$ and $\mathrm{B}$ with respect to $\Omega$ illustrated in Figure 11.
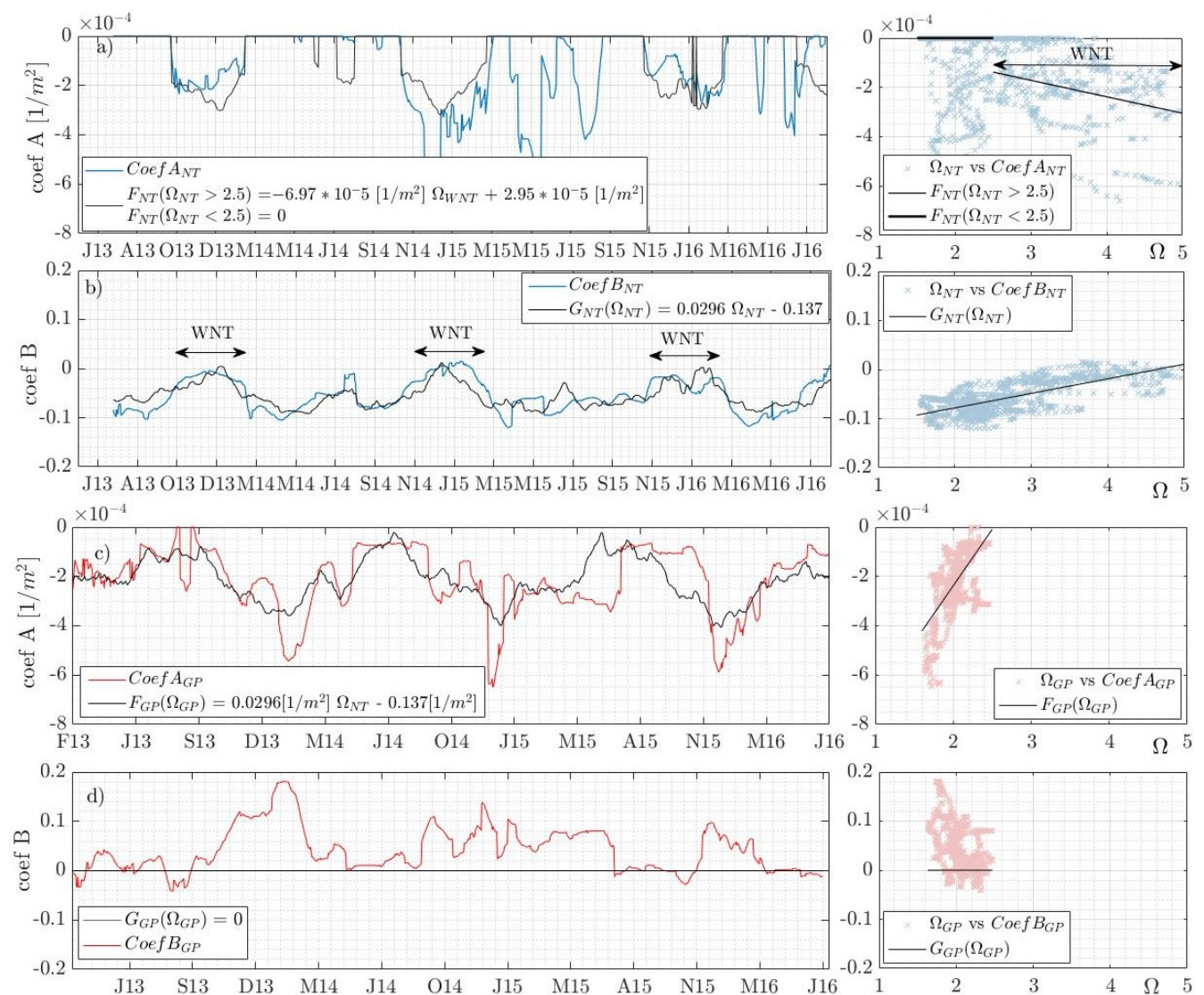

Figure 11. Left Figures: represents the shape coefficients evolution for Nha Trang $(\mathbf{a}, \mathbf{b})$ and Grand Popo (c,d). Right Figures: shape coefficients vs. their respective $\Omega$. Represented in black are the linear regressions obtained between the shape coefficients A and B respect to $\Omega$. 
It is interesting to note that the strongest correlations between the shape coefficients with $\Omega$ is not the same for both beaches. For Nha Trang the dominant coefficients is coef. B (Figure 11b left) and for Grand Popo is coef. A (Figure 11c left). For Nha Trang it is possible to appreciate a seasonal fluctuations of the shapes coefficients; coefficient $B$ tends to zero when there is a terrace profile meaning that the linear terms goes to zero in these cases. It is found that the dominant coefficient for Nha Trang (coef. B) and Grand Popo (coef. A), are well captured by this linear models $G_{N T}(\Omega)$ and $F_{G P}(\Omega)$ respectively (Figure $11 \mathrm{~b}, \mathrm{c}$ ). Even if less accurate, the trend evolution of coef. A for WTN is also captured by the linear model $F_{N T}\left(\Omega_{W N T}\right)$ (Figure 11a left). Moreover, at Grand Popo it was proved that coef. B does not influence the obtained results. This conclusion was reached by performing two tests, one with a linear regression between $\Omega$ and coef. B and the other one with $G_{G P}(\Omega)=0$ (right Figure 11d), the results were basically the same for both cases. Thus to simplify GP model $\mathrm{G}(\Omega)$ is zero.

The results of each model are illustrated in Figures 12 and 13 for these two sites respectively. The evaluation of the model is estimated by the differences between the monthly average evolution of the terrace width $\left(L_{t}\right)$ and the upper swash slope $(\beta)$ obtained from field data with the values calculated from the model ( $L_{t}$ model and $\beta$ model). The rootmean-square error (RMSE) and root-mean-square-relative error (RMSRE, \%) are shown in Table 3.

Table 3. Root mean square error(RMSE, $m$ ) and relative error (RMSRE, \%) obtained from the model prediction.

\begin{tabular}{ccccc}
\hline & \multicolumn{2}{c}{ RMSE } & \multicolumn{2}{c}{ RMSRE } \\
\cline { 2 - 5 } & Lt-Lt Model & $\boldsymbol{\beta}$ - $\boldsymbol{\beta}$ Model & Lt-Lt Model & $\boldsymbol{\beta}$ - $\boldsymbol{\beta}$ Model \\
\hline Nha Trang & $2.9 \mathrm{~m}$ & 0.04 & $21 \%$ & $46 \%$ \\
Grand Popo & $5.9 \mathrm{~m}$ & 0.05 & $14 \%$ & $28 \%$ \\
\hline
\end{tabular}

Note that the values correspond well with the discussion in Section 3.2, that there are two families of LTT beaches: one controlled by the swash zone (SwRB) and the other by the surf zone (SRB). The highest RSMRE corresponds to the swash slope evolution $($ RSMRE $=46 \%)$ at Nha Trang which is the case of SRB, thus it make sense that the variations of the swash slope $(\beta)$ can not be capture with the variation of off-shore parameters such as the Dean number $(\Omega)$ as it is controlled by surf zone process.

It is important to analyse not only the errors obtained by the models predictions, but also the trends of the morpho-parameters $\left(L_{t}\right.$ and $\left.\beta\right)$, Figures 12 and 13. From these comparisons, one can observe that the general trend of the beach profiles over time is recovered by the model (see Figures $12 \mathrm{a}, \mathrm{b}$ and $13 \mathrm{a}, \mathrm{b}$ for comparisons). A more quantitative comparison is also proposed by plotting the evolution of $L_{t}$ and $\beta$ (from data and model) as a function of time in Figures 12c,d and 13c,d. Seasonal variation seems to be well captured by the model. This is more clearly highlighted by $L_{t}$ at Nha Trang (Figure 12c) and $\beta$ at Grand Popo (Figure 13d). On the other hand, rapid fluctuations are slightly more poorly prescribed by the model, indicating that transient evolution probably includes physical ingredients not accounted for in the Dean number $\Omega$. 


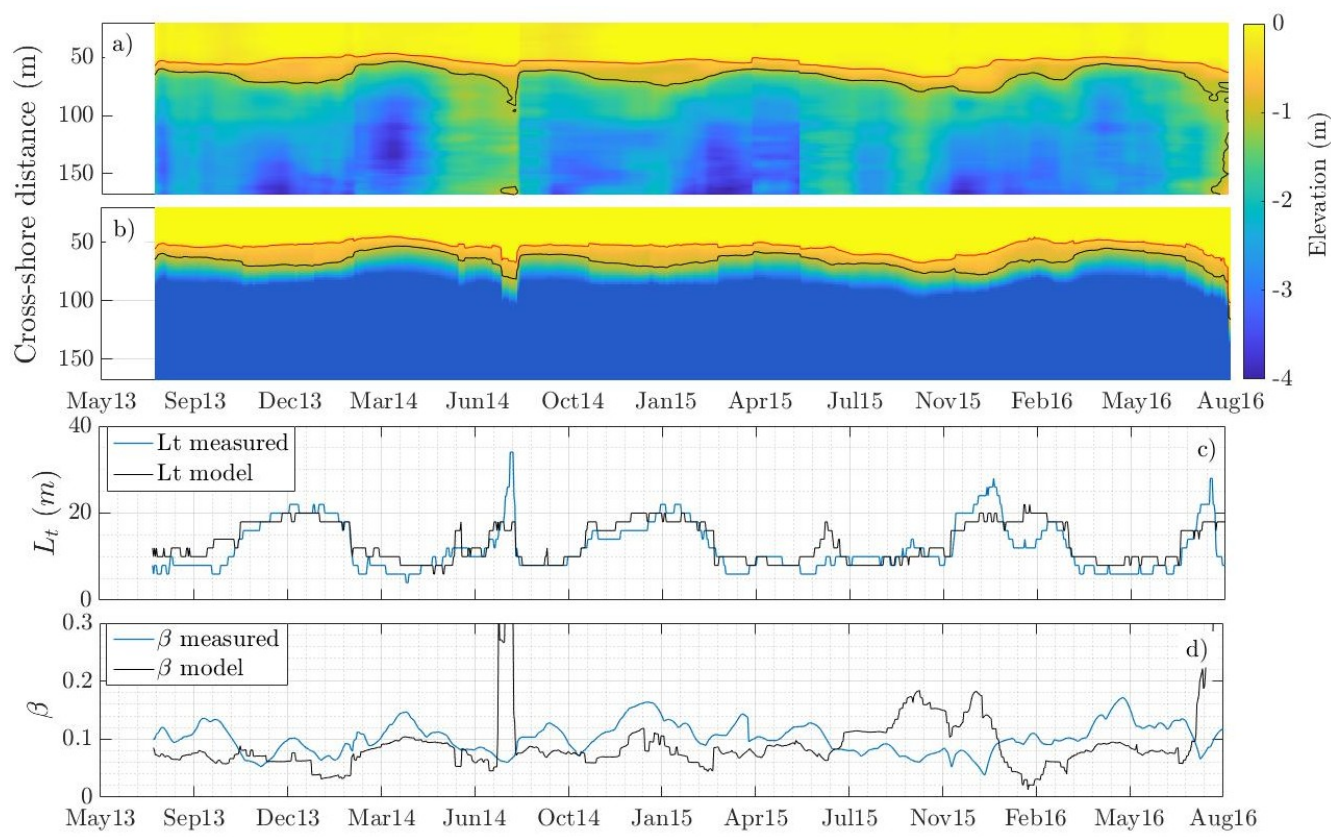

Figure 12. Nha Trang model results. (a): Monthly average bathymetry evolution. (b): Bathymetry evolution calculated with the parametric model. (c): terrace width evolution obtained from field data and those calculated from the parametric model ( $L_{t} \& L_{t}$ model). (d): upper swash slope evolution obtained from field data and those calculated from the parametric model ( $\beta \& \beta$ model).

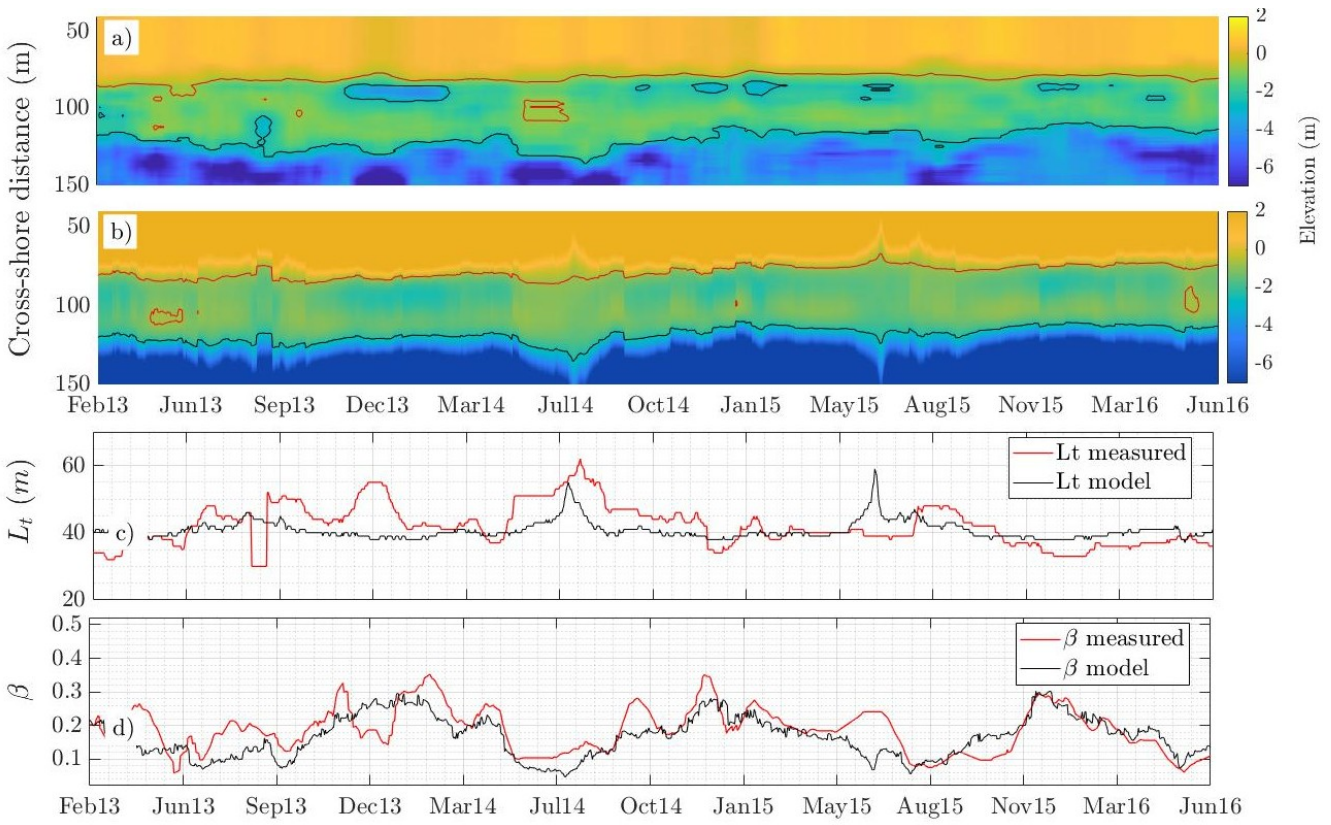

Figure 13. Grand Popomodel results. (a): Monthly average bathymetry evolution. (b): Bathymetry evolution calculated with the parametric model. (c): terrace width evolution obtained from field data and those calculated from the parametric model ( $L_{t} \& L_{t}$ model). (d): upper swash slope evolution obtained from field data and those calculated from the parametric model ( $\beta \& \beta$ model).

\section{Conclusions}

From the morphological scaling at Nha Trang and Grand Popo, two different morphological responses of the inner-surf zone were identified depending on wave climate. When swash processes dominate with large reflection such as in Grand Popo, the terrace can be seen as a result of the sediment deposition from the swash zone (and reflected waves) and not directly driven by incoming waves, we refer this case as Swash Regulated 
Beach (SwRB). The other situation refers to a Surf Regulated Beach (SRB) being the case of Nha Trang where the terrace is active at dissipating wave energy hence the dynamics of the swash zone is regulated by the surf zone and not by offshore wave forcing. This two families (SwRB and SRB) were also observed from the results of the simple parametric model proposed in Section 4. based on the Dean number $(\Omega)$ as a control parameter. Note that this simplified model should be use to help understand LTT environments and not as a predictor as a single parameter is surely not enough to describe the whole spectrum of beaches. Such single parameter analysis can not explain and capture the entire hydro-morphodyanamics of the system: as for instance site-to-site unification remains difficult, but also rapid variation of the upper swash slope $(\beta)$ are not captured. This remains an open question that would require more field data and probably a more refined out-of-equilibrium state model.

Author Contributions: Conceptualization, I.M.M.; methodology, I.M.M.; investigation, I.M.M.; supervised L.L. and R.A.; validation L.L. and R.A.; Writing—original draft I.M.M.; Writing—review and editing L.L. and R.A. All authors have read and agreed to the published of the manuscript.

Funding: This research was funded by the French National Centre for Scientific Research (CNRS) through the 80 PRIME project (multi-team interdisciplinary research project).

Institutional Review Board Statement: Not applicable.

Informed Consent Statement: Not applicable.

Acknowledgments: The authors would like to acknowledge all colleagues who participated in the collection of the field data.

Conflicts of Interest: The authors declare no conflict of interest.

Abbreviations
$\begin{array}{ll}\text { The following abbreviations are used in this manuscript: } \\ \text { LTT } & \text { Low tide terrace } \\ \text { TBR } & \text { Transverse var and rip state } \\ \text { SNT } & \text { Summer Nha Trang cross-shore profiles } \\ \text { WNT } & \text { Winter Nha Trang cross-shore profiles } \\ \text { GP } & \text { Grand Popo cross-shore profiles } \\ \text { SRB } & \text { Surf regulated beach } \\ \text { SwRB } & \text { Swash regulated beach } \\ \text { RMSE } & \text { Root mean square error } \\ \text { RMSRE } & \text { Root mean square relative error } \\ \Omega & \text { Dean number } \\ h_{S} & \text { Wave height } \\ T_{p} & \text { Wave period } \\ W_{s} & \text { Sediment fall velocity } \\ L_{t} & \text { Terrace width } \\ \beta & \text { Beach face slope } \\ H_{t} & \text { water depth on the terrace } \\ \lambda & \text { water wavelenght }\end{array}$

\section{References}

1. Gallop, S.L.; Kennedy, D.M.; Loureiro, C.; Naylor, L.A.; Muñoz-Pérez, J.J.; Jackson, D.W.; Fellowes, T.E. Geologically controlled sandy beaches: Their geomorphology, morphodynamics and classification. Sci. Total Environ. 2020, 731, 139123. [CrossRef] [PubMed]

2. Wright, L.D.; Short, A.D. Morphodynamic variability of surf zones and beaches: A synthesis. Mar. Geol. 1984, 56, 93-118. [CrossRef]

3. Power, H.E.; Baldock, T.E.; Callaghan, D.P.; Nielsen, P. Surf zone states and energy dissipation regimes-a similarity model. Coast. Eng. J. 2013, 55, 1350003-1-1350003-18. [CrossRef]

4. Masselink, G.; Short, A.D. The effect of tide range on beach morphodynamics and morphology: A conceptual beach model. J. Coast. Res. 1993, 9, 785-800. 
5. Gourlay, M.R. Beaches, profiles, processes and permeability. In Proceedings of the 17th International Conference on Coastal Engineering, Sydney, Australia, 23-28 March 1980; pp. 1320-1339. [CrossRef]

6. Short, A.D. The role of wave height, period, slope, tide range and embaymentisation in beach classifications: A review. Rev. Chil. Hist. Nat. 1996, 69, 589-604.

7. Miles, J.R.; Russell, P.E. Dynamics of a reflective beach with a low tide terrace. Cont. Shelf Res. 2004, 24, 1219-1247. [CrossRef]

8. Stringari, C.E.; Power, H.E. The Fraction of Broken Waves in Natural Surf Zones. J. Geophys. Res. Ocean. 2019, 124, 9114-9140. [CrossRef]

9. Lemos, C.; Floc'h, F.; Yates, M.; Le Dantec, N.; Marieu, V.; Hamon, K.; Cuq, V.; Suanez, S.; Delacourt, C. Equilibrium modeling of the beach profile on a macrotidal embayed low tide terrace beach. Ocean Dyn. 2018, 68, 1207-1220. [CrossRef]

10. Anfuso, G.; Ruiz, N. Morfodinámica de una playa mesomareal expuesta con terraza de bejamar (Faro, Sur de Portugal). Cienc. Mar. 2004, 30, 575-584. [CrossRef]

11. Short, A.; Jackson, D. Beach morphodynamics (chapter). Treatise Geomorphol. 2013, 10, 106-129.

12. Almeida, L.P.; Almar, R.; Blenkinsopp, C.; Senechal, N.; Bergsma, E.; Floc'h, F.; Caulet, C.; Biausque, M.; Marchesiello, P.; Grandjean, P.; et al. Lidar observations of the swash zone of a low-tide terraced tropical beach under variable wave conditions: The Nha Trang (Vietnam) COASTVAR experiment. J. Mar. Sci. Eng. 2020, 8, 302. [CrossRef]

13. Almar, R.; Hounkonnou, N.; Anthony, E.J.; Castelle, B.; Senechal, N.; Laibi, R.; Mensah-Senoo, T.; Degbe, G.; Quenum, M.; Dorel, M.; et al. The Grand Popo beach 2013 experiment, Benin, West Africa: From short timescale processes to their integrated impact over long-term coastal evolution. J. Coast. Res. 2014, 70, 651-656. [CrossRef]

14. Almar, R.; Almeida, P.; Blenkinsopp, C.; Catalan, P. Surf-swash interactions on a low-tide terraced beach. J. Coast. Res. 2016, 1, 348-352. [CrossRef]

15. Almeida, L.P.; Almar, R.; Marchesiello, P.; Benshila, R.; Martins, K.; Blenkinsopp, C.; Floc’h, F.; Ammann, J.; Grandjean, P.; Viet, N.T.; et al. Swash zone dynamics of a sandy beach with low tide terrace during variable wave and tide conditions. Proc. Journées Natl. Génie Côtier-Génie Civ. 2016, 137-144. [CrossRef]

16. Alexander, L.; Allen, S.; Bindoff, N.L.; Francois-Marie, B.; Church, J.; Cubasch, U.; Gregory, J.; Hartmann, D.; Jansen, E.; Kirtman, B.; et al. Climate Change 2013: The Physical Science Basis. Contribution of Working Group I to the Fifth Assessment Report of the Intergovernmental Panel on Climate Change. IPCC 2013, AR5, 1535.

17. Ondoa, G.A.; Almar, R.; Kestenare, E.; Bahini, A.; Houngue, G.H.; Jouanno, J.; Du Penhoat, Y.; Castelle, B.; Melet, A.; Meyssignac, B.; et al. Potential of video cameras in assessing event and seasonal coastline behaviour: Grand Popo, Benin (Gulf of Guinea). J. Coast. Res. 2016, 1, 442-446. [CrossRef]

18. Thuan, D.H.; Almar, R.; Marchesiello, P.; Viet, N.T. Video sensing of nearshore bathymetry evolution with error estimate. J. Mar. Sci. Eng. 2019, 7, 233. [CrossRef]

19. Bergsma, E.W.J.; Almar, R. Video-based depth inversion techniques, a method comparison with synthetic cases. Coast. Eng. 2018, 138, 199-209. [CrossRef]

20. Almar, R.; Ranasinghe, R.; Snchal, N.; Bonneton, P.; Roelvink, D.; Bryan, K.R.; Marieu, V.; Parisot, J.P. Video-Based detection of shorelines at complex MesoMacro tidal beaches. J. Coast. Res. 2012, 28, 1040-1048. [CrossRef]

21. Lippmann, T.C.; Holman, R.A. Quantification of sand bar morphology: A video technique based on wave dissipation. J. Geophys. Res. Ocean. 1989, 94, 995-1011. [CrossRef]

22. Holman, R.A.; Sallenger, A.H., Jr.; Lippmann, T.C.; John, W.; Holman, B.R.A.; Sallenger, A.H. The Application of Video Image Processing to the Study of Nearshore Processes. Oceanography 1993, 6, 78-85. [CrossRef]

23. Ondoa, G.A.; Bonou, F.; Tomety, F.S.; du Penhoat, Y.; Perret, C.; Degbe, C.G.E.; Almar, R. Beach response to wave forcing from event to inter-annual time scales at grand popo, benin (Gulf of Guinea). Water 2017, 9, 447. [CrossRef]

24. Schwartz, M.L. The Bruun Theory of Sea-Level Rise as a Cause of Shore Erosion. J. Geol. 1967, 75, 76-92. [CrossRef]

25. Dean, R.G. Equilibrium Beach Profiles: Characteristics and Applications. J. Coast. Res. 1991, 7, 53-84. 